\title{
In vivo hepatic differentiation potential of human cord blood-derived mesenchymal stem cells
}

\author{
SINYOUNG KIM, HAN-SOO KIM, EUGENE LEE and HYUN OK KIM \\ Department of Laboratory Medicine, Yonsei University College of Medicine, Seoul, Republic of Korea
}

Received December 9, 2010; Accepted January 28, 2011

DOI: $10.3892 /$ ijmm.2011.627

\begin{abstract}
Although recent studies have demonstrated the in vitro hepatic differentiation potential of mesenchymal stem cells (MSCs), the evidence supporting the in vivo engraftment of MSCs, hepatic differentiation and improvement of hepatic function is still lacking. We investigated in vivo hepatic differentiation potential and therapeutic effect of cord blood derived-MSCs (CBMSCs) transplantation in a cirrhotic rat model. CBMSCs $\left(2 \times 10^{6}\right)$ were infused in Wistar rats with thioacetamide-induced chronic liver injury. Biochemical markers, liver fibrosis and engraftment of CBMSCs were assessed. Infused CBMSCs were detected in the perivascular or fibrous region of the liver and did not acquire mature hepatic phenotypes. There was no difference in biochemical markers and in the area of liver fibrosis between the experimental and placebo groups. After infusion of CBMSCs in our experimental cirrhotic rat model we did not observe an improvement of liver function and liver fibrosis. Inversely, CBMSCs could have a pro-fibrogenic potential suggesting that a cautious approach is required in future research.
\end{abstract}

\section{Introduction}

Liver transplantation is currently the only successful treatment for acute hepatic failure or end stage liver disease. However, several problems are associated with liver transplantation: lack of donors, surgical complications, rejection, and high cost. Hepatocyte transplantation has been the alternative option for bridging patients to liver transplantation. But, primary hepatocytes are only available from a restricted number of donor organs, usually livers not allocated for organ transplantation (1). Also primary hepatocytes have a poor proliferative potential, which probably does not suffice to effectively repopulate the host liver and are difficult to maintain in an in vitro culture without loss of functions (2).

Correspondence to: Dr Hyun Ok Kim, Department of Laboratory Medicine, Yonsei University College of Medicine, CPO Box 8044, 134 Sinchon-dong, Seodaemun-gu, 120-752 Seoul, Republic of Korea E-mail: hyunok1019@yuhs.ac

Key words: mesenchymal stem cell, cord blood, hepatic differentiation
Several studies have shown that hematopoietic stem cells from the bone marrow have the capacity to differentiate into a variety of non-hematopoietic cells such as liver, heart, and brain (3-6). Even multi-organ differentiation has been demonstrated from hematopoietic stem cells and from multipotent adult progenitor cells $(7,8)$. However, hematopoietic stem cells contribute little to hepatocyte formation under either physiological or pathological conditions, although they provide cytokines and growth factors that promote hepatocyte functions by paracrine mechanisms (9).

The other potential candidate stem cells for therapy of an injured liver are mesenchymal stem cells (MSCs), which could be obtained from different sources such as the bone marrow, cord blood, amniotic fluid, placenta, or adipose tissue (10-14). Among the sources of MSCs, cord blood has a number of advantages in cell procurement, such as abundance, lack of donor attrition, and low risk of viral transmission such as transmission of herpes family viruses. Furthermore, stem cells in this neonatal blood are less mature than in other adult cells so that they do not produce a strong immune rejection. For these reasons, cord blood could be a prominent source of cells for transplantation in various diseases.

The hepatocyte differentiation potential of MSCs has been described (15-17). After in vitro stimulation with hepatocyte growth factor (HGF), dexamethasone, and oncostatin $\mathrm{M}$ (OSM), MSCs could differentiate into hepatocyte-like cells. Administration of MSCs from various sources has been shown to improve liver injury in a chronic model of liver cirrhosis $(18,19)$. However, unequivocal evidence supporting the in vivo ability of transplanted human MSCs to enter liver parenchyma by circulation and to acquire markers of hepatocyte-like differentiation is still lacking (20).

The purpose of this study was to evaluate the in vivo hepatic differentiation potential of umbilical cord bloodderived MSCs (CBMSCs) and to assess whether CBMSCs are capable of reducing liver cirrhosis and improving hepatic function in a rat model of chronic liver injury.

\section{Materials and methods}

Isolation of CBMSCs. Cord blood samples from full-term deliveries were collected and mononuclear cells (MNCs) were separated within $6 \mathrm{~h}$ of collection using density gradient centrifugation. MNCs were washed three times with phosphate-buffered saline (PBS) and were set in culture at a 
Table I. Biochemical markers of liver function in the control and experimental groups 1 and 4 weeks post-transplantation.

\begin{tabular}{lccccc}
\hline & \multicolumn{3}{c}{1 week } & & \multicolumn{2}{c}{4 weeks } \\
\cline { 2 - 3 } \cline { 5 - 6 } & $\begin{array}{c}\text { Control } \\
\text { group }(\mathrm{n}=6)\end{array}$ & $\begin{array}{c}\text { Experimental } \\
\text { group }(\mathrm{n}=10)\end{array}$ & & $\begin{array}{c}\text { Control } \\
\text { group }(\mathrm{n}=6)\end{array}$ & $\begin{array}{c}\text { Experimental } \\
\text { group }(\mathrm{n}=8)\end{array}$ \\
\hline Ammonia $(\mu \mathrm{mol} / \mathrm{l})$ & $107 \pm 20$ & $114 \pm 41$ & $112 \pm 22$ & $128 \pm 34$ \\
Total protein $(\mathrm{g} / \mathrm{dl})$ & $5.9 \pm 0.3$ & $6 \pm 0.3$ & $6 \pm 0.3$ & $6 \pm 0.3$ \\
Albumin $(\mathrm{g} / \mathrm{dl})$ & $2.5 \pm 0.2$ & $2.6 \pm 0.1$ & & $2.6 \pm 0.2$ & $2.6 \pm 0.1$ \\
Total bilirubin $(\mathrm{mg} / \mathrm{dl})$ & $1.1 \pm 0.2$ & $1 \pm 0.2$ & & $0.6 \pm 0.4$ & $0.6 \pm 0.3$ \\
AST (IU/l) & $100 \pm 29$ & $94 \pm 16$ & & $85 \pm 8$ & $104 \pm 13$ \\
ALT (IU/l) & $52 \pm 18$ & $44 \pm 9$ & $70 \pm 14$ & $71 \pm 17$ \\
\hline
\end{tabular}

density of $3 \times 10^{6}$ cells $/ \mathrm{cm}^{2}$ into fibronectin (Sigma-Aldrich, St. Louis, MO) coated 6-well plates (Nunc, Rochester, NY) in endothelial growth medium-2 (EGM-2, Gibco, Grand Island, NY) or MSCGM medium (Cell Systems, St. Katharinen, Germany). Media were changed every 3 days. After colony formation between days 14 and 20, cells were harvested using $0.1 \%$ trypsin-EDTA solution (Gibco) and cultured thereafter in Dulbecco's modified Eagle's medium (DMEM; Gibco) containing $10 \%$ fetal bovine serum (FBS).

In vivo transplantation of CBMSCs. Six-week-old female Wistar rats (Oriental Bio, Seongnam, Korea) were used. All animal procedures were approved by the Institutional Animal Care and Use Committee. Chronic liver injury was induced by intraperitoneal administration of thioacetamide (TAA, SigmaAldrich), $300 \mathrm{mg} / \mathrm{kg}$ twice weekly for 6 weeks, as previously described (21). After 6 weeks of TAA injection, the rats were randomly divided into 2 groups: (i) a DMEM infused control group ( $\mathrm{n}=12)$, and (ii) a CBMSC infused experimental group $(\mathrm{n}=18)$. In the experimental group, $2 \times 10^{6} \mathrm{CBMSCs}$ suspended in $400 \mu 1$ of DMEM were injected into the tail vein. All rats of both groups were further administered an intraperitoneal injection of TAA at the same dose twice weekly until sacrificed. All rats were immunosuppressed with a daily intraperitoneal injection of $10 \mathrm{mg} / \mathrm{kg} /$ day of cyclosporine A (Cipol; Chong Kun Dang, Seoul, Korea), from $24 \mathrm{~h}$ before the transplantation to the day of sacrifice. Liver tissues and blood samples were obtained after 1 or 4 weeks of transplantation, after the animals were sacrificed.

Immunohistochemical analysis. Liver tissues were fixed in buffered formalin, embedded in paraffin. Liver sections $(2 \mu \mathrm{m})$ were deparaffinized and rehydrated. Antigen retrieval was performed by incubating in boiling water containing $10 \mathrm{mM}$ sodium citrate buffer ( $\mathrm{pH}$ 6.0) for $15 \mathrm{~min}$. Endogenous peroxidase was inactivated with $0.3 \%$ hydrogen peroxide for $30 \mathrm{~min}$. Non-specific staining was eliminated by an additional blocking step with $1 \%$ bovine serum albumin and $0.1 \%$ Tween-20 in phosphate buffer for $1 \mathrm{~h}$ at $37^{\circ} \mathrm{C}$. Rehydrated slides were then incubated overnight at $4^{\circ} \mathrm{C}$ with primary antibodies as follows: anti-HepPar1 (1:100, M7158; DakoCytomation, Heverlee, Belgium), anti-human cytokeratin (CK)-18 (1:100, M7010; DakoCytomation), anti-human CK-8 (1:100, MAB3414; Chemicon, Hants, England), anti-human mitochondria (1:50, MAB1273; Chemicon), and anti-human nuclei (1:50, MAB1281; Chemicon). After unbound primary antibodies were washed off, the immunoreactivity was visualized using an EnVision detection kit (DakoCytomation) and diaminobenzidine. Sections were counterstained with hematoxylin and mounted for analysis.

Biochemical analysis. Blood samples were centrifuged at 3,500 x g for $10 \mathrm{~min}$ and then plasma was immediately separated. The following parameters were measured on a Hitachi 7600 automated chemistry analyzer (Hitachi, Tokyo, Japan): ammonia, total protein, albumin, total bilirubin, aspartate aminotransferase (AST), and alanine aminotransferase (ALT).

Quantitative analysis of liver fibrosis. For the evaluation of liver fibrosis, picrosirius red staining was performed using $0.1 \%$ picrosirius red solution as previously described (22). The area of liver fibrosis stained with picrosirius red was quantified using ImageJ software (4 randomly selected areas per slide, 4 slides for each rat).

Statistical analysis. All results are expressed as mean \pm standard deviation (SD). Statistical differences were assessed using the Mann-Whitney $U$ test, where $\mathrm{p}<0.05$ was considered statistically significant.

\section{Results}

In vivo hepatic differentiation of CBMSCs in the murine cirrhotic model. The engraftment and hepatic differentiation of CBMSCs in the liver of recipient rats were analyzed at 1 or 4 weeks after transplantation. Human hepatocytes (positive for anti-HepPar1 antibody) were very rarely detected as single cells located near portal veins. However, the HepParl-positive cells did not stain for the human CK-18 and CK-8 antigen, as shown in human liver sections used as a positive control. (Fig. 1). These results do not amount to full evidence of the formation of mature human hepatocytes, but the lack of CK-18 and CK- 8 could be explained by an immature phenotype of HepPar-1 positive cells or by cellular fusion that results in a cell type characterized by chimeric gene and protein expression. Tracing of human cells into recipient rat livers was detected by immunohistochemical detection of human 


\section{$\mathbf{A}$}
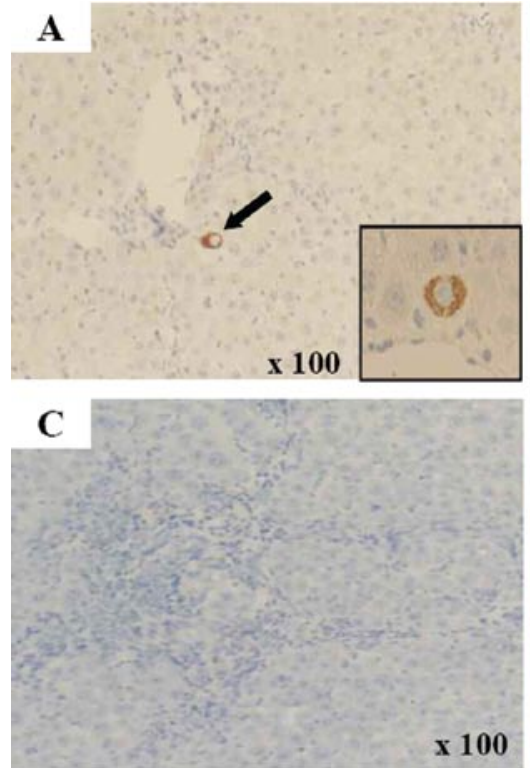

E

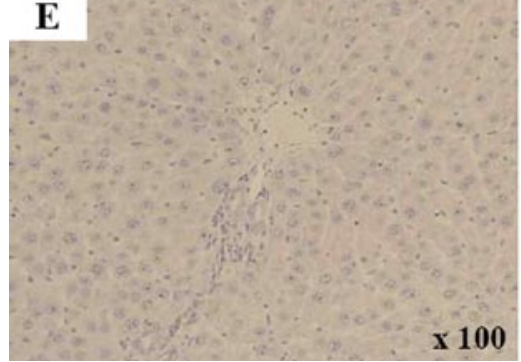

B

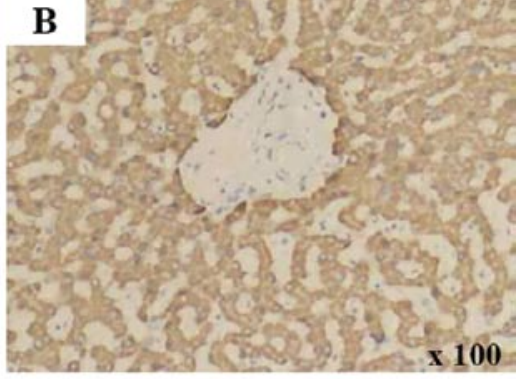

D
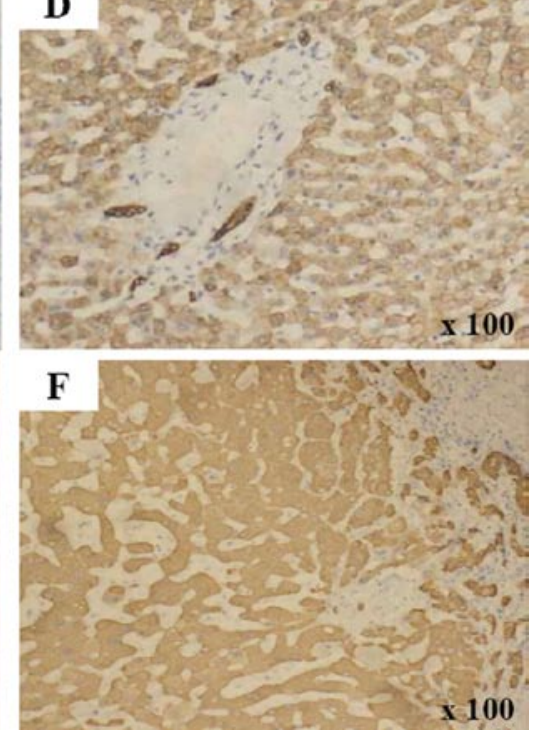

Figure 1. Representative figures showing minimal engraftment of cord blood derived-MSCs (CBMSCs) in the rat liver. (A) Infused CBMSCs were detected immunohistochemically by the expression of anti-human hepatocyte specific HepParl positive cells in the periportal area. There are no cells stained with anti-human CK18 (C) or anti-human CK8 (E) which detect human, but not rat, hepatocytes. Control human liver samples were stained with anti-HepPar 1 (B), anti-human CK18 (D), and anti-human CK8 (F) showing detection of the respective human antigens. Cells were counterstained with hematoxylin.

\section{A. Anti-human nuclei $\mathrm{Ab}$}
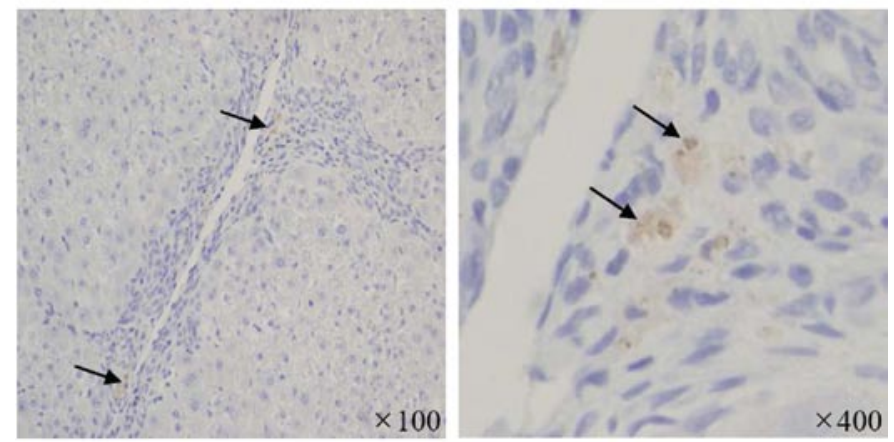

\section{B. Anti-human mitochondria $\mathrm{Ab}$}
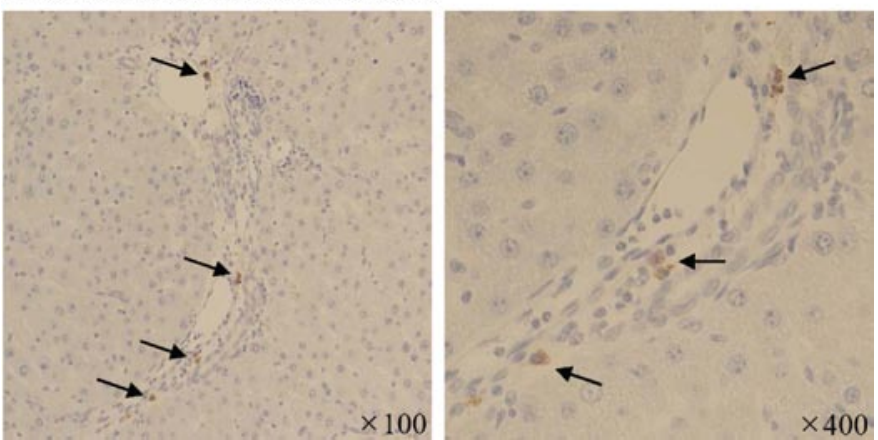

Figure 2. Detection of human-derived cells by immunohistochemistry of liver section with anti-human nuclei antibody (A) and anti-human mitochondria antibody (B). Cells were counterstained with hematoxylin. 

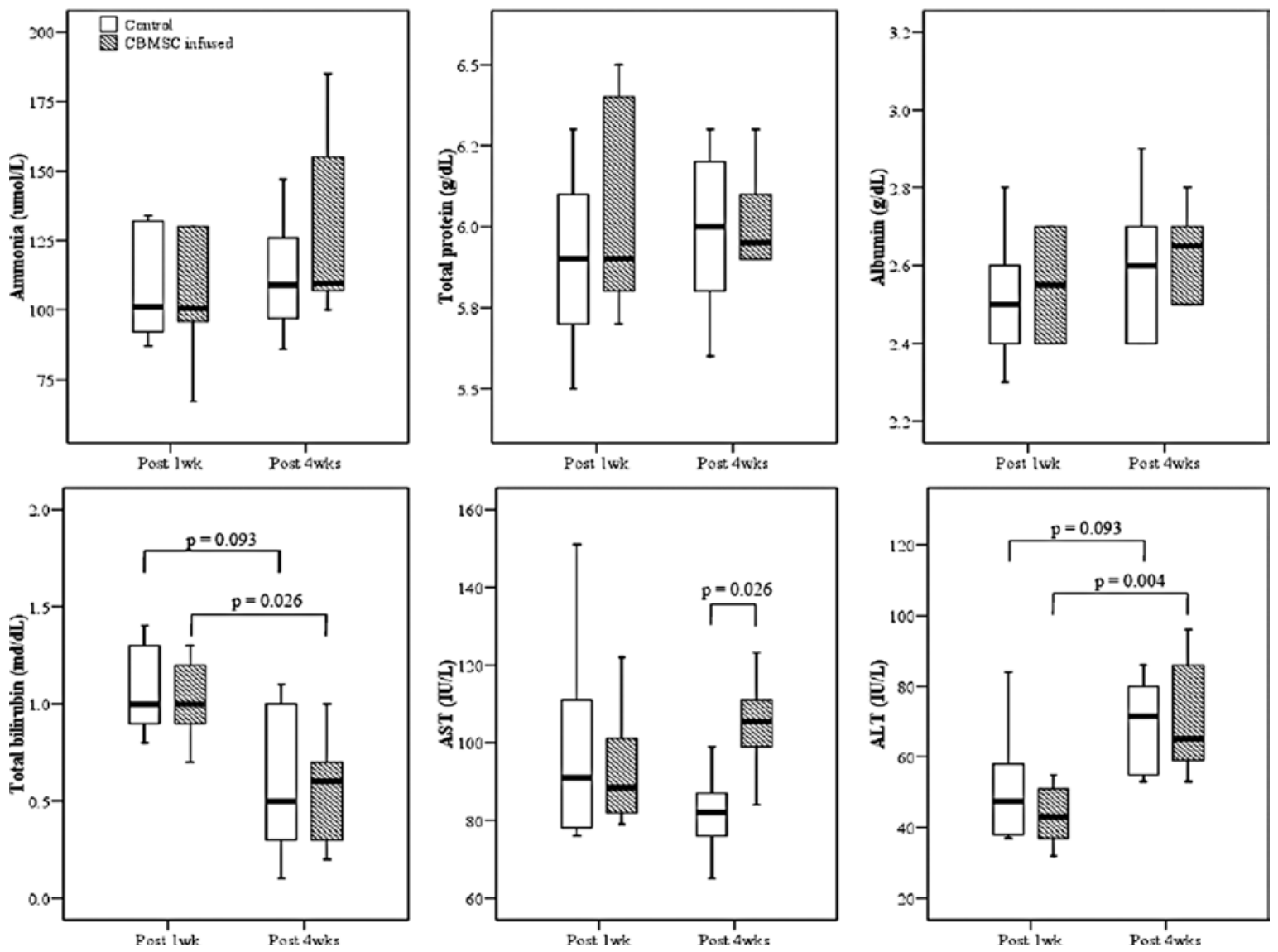

Figure 3. Biochemical markers of liver injury and function. Concentrations of ammonia, total protein, albumin, total bilirubin, AST and ALT in blood samples of the control and experimental groups. AST, aspartate aminotransferase; ALT, alanine aminotransferase.

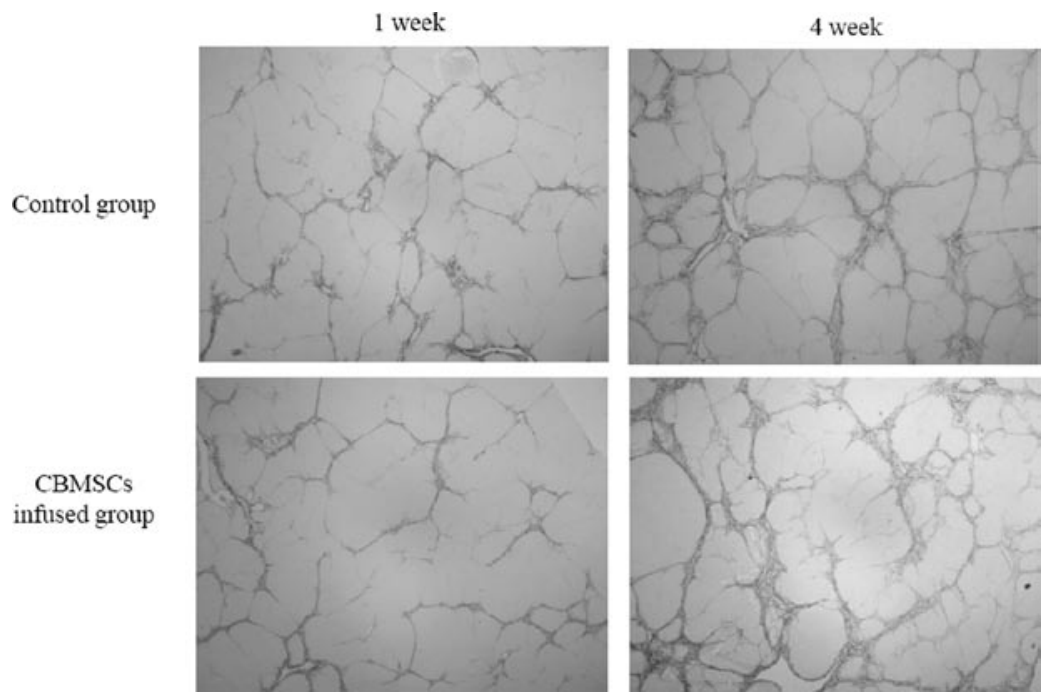

Figure 4. Fibrosis quantification in picrosirius red-stained field. Representative figures showing fibrosis area in the CBMSCs infused- and control groups after 1 or 4 weeks of transplantation. CBMSCs, cord blood derived-MSCs.

nuclei and human mitochondria. Some human CBMSCs with a fibroblast-like shape were incorporated in regions of the fibrous septal, perivascular and periportal areas (Fig. 2).

Alteration of liver function after transplantation of CBMSCs. Serum markers related to hepatic function, such as ammonia, total protein, albumin, total bilirubin, AST and ALT were measured after 1 or 4 weeks of transplantation. There were no statistically significant differences between the control group and the experimental group in terms of their ammonia, total protein and albumin levels (Table I, Fig. 3). The concentration of total bilirubin was significantly decreased with TAA administration; on the contrary, the activity of ALT was significantly increased. 
Table II. Quantitative measurement of liver fibrosis expressed as \% collagen deposited area/total area.

\begin{tabular}{lllll}
\hline & \multicolumn{2}{c}{ Control group } & \multicolumn{2}{c}{ Experimental group } \\
\cline { 2 - 3 } 1 week post-transplantation & $2.05 \pm 1.37$ & $(\mathrm{n}=73)$ & $2.25 \pm 2.01$ & $3.58 \pm 2.24 \quad(\mathrm{n}=141)$ \\
4 weeks post-transplantation & $3.26 \pm 2.76$ & $(\mathrm{n}=80)$ & $(\mathrm{n}=81)$ \\
\hline
\end{tabular}

$\mathrm{n}$, number of examined fields.

In order to quantify the amount of fibrosis over time comparing the control and experimental group, picrosirius red stained areas, representing collagen deposition, were measured. After 1 week of transplantation, experimental group had $2.25 \pm 2.01 \%$ of collagen in the liver, compared to $2.05 \pm 1.37 \%$ of control group (Table II). These results are not significantly different. After 4 weeks of transplantation, the CBMSC infused group revealed a fibrosis area of $3.58 \pm 2.24 \%$, compared to $3.26 \pm 2.76 \%$ in the control group. The area of liver fibrosis after 4 weeks of CBMSCs transplantation was significantly more than that in the control group ( $p=0.021$, Fig. 4).

\section{Discussion}

The potential to differentiate into endodermal cells, such as hepatocytes has been investigated in vitro with human MSCs from the bone marrow $(8,15,23)$, umbilical cord blood $(23,24)$, and adipose tissue (19). Initially, Schwartz et al induced multipotent adult progenitor cells (MAPCs) into cells with morphological, phenotypical and functional characteristics of hepatocytes in vitro upon exposure to well-defined hepatogenic factors (8). However, these culture conditions yielded a mixture of epithelioid cells and other cell types. Therefore, attempts were made to improve the hepatic differentiation process through exposure to liver-specific factors in a sequential time-dependent manner (25) or via epigenetic modifications using histone deacetylase inhibitors, such as DMSO, sodium butyrate or trichostatin A.

Even though the differentiation potential of MSCs into hepatocytes in vitro has been demonstrated, there are pros and cons regarding the therapeutic efficacy of MSCs in acute or chronic liver injury. Sakaida et al (22) demonstrated a significant reduction of liver fibrosis and an increase of albumin concentration by transplanting mononuclear cells in mice. Similarly, Oyagi et al (26) have reported that MSCs cultured with HGF are capable of increasing albumin concentration and reducing fibrosis in rats, an effect that was not observed in MSCs cultured without HGF. On the other hand, in murine models involving bone marrow ablation, transplanted bone marrow cells were reported to engraft to the liver during chronic liver diseases and to significantly contribute to liver fibrosis by differentiating into pro-fibrogenic myofibroblastlike cells, with hepatocyte-like transdifferentiation again being a rare event (27).

In this study, ex vivo expanded CBMSCs were transplanted into TAA-injured rat to assess the hepatic differentiation potential of CBMSCs and therapeutic efficacy in a chronic liver injury model. Although the experimental animals were immunosuppressed by cyclosporin A, effective repopulation by differentiated CBMSCs was not achieved. This extremely low repopulation efficiency might be a consequence of the xenotransplantation, with the rat liver failing to provide the proper cell-cell or cell-matrix communications required for efficient integration of the human cells. In chronic liver injury, in vivo differentiation of intravenously transplanted CBMSCs into hepatocyte-like cells represents a relatively rare and quantitatively unsatisfactory rare event.

Along with the low efficiency of in vivo hepatic differentiation, liver function measured by blood parameters was not significantly improved. It is widely recognized that experimental models of liver fibrosis have a major problem: the degree of fibrosis in each animal is highly heterogeneous. Whereas some animals show intense extracellular matrix components deposition, others are only mildly affected. Therefore, the appropriate selection of experimental animals would be an important factor for future studies. In agreement with the biochemical results, we found that CBMSCs did not reduce liver fibrosis. Given the findings of this study, if CBMSCs could have a pro-fibrogenic potential, a possible outcome may be enhanced fibrosis of the liver, suggesting that a cautious approach is required.

\section{Acknowledgements}

This study was supported by a faculty research grant of the Yonsei University College of Medicine (6-2008-0109).

\section{References}

1. Lee SW, Wang X, Chowdhury NR and Roy-Chowdhury J: Hepatocyte transplantation: state of the art and strategies for overcoming existing hurdles. Ann Hepatol 3: 48-53, 2004.

2. Walldorf J, Aurich H, Cai H, Runge D, Christ B, Strom SC and Fleig WE: Expanding hepatocytes in vitro before cell transplantation: donor age-dependent proliferative capacity of cultured human hepatocytes. Scand J Gastroenterol 39: 584-593, 2004.

3. Petersen BE, Bowen WC, Patrene KD, Mars WM, Sullivan AK, Murase N, Boggs SS, Greenberger JS and Goff JP: Bone marrow as a potential source of hepatic oval cells. Science 284 : 1168-1170, 1999.

4. Theise ND, Nimmakayalu M, Gardner R, Illei PB, Morgan G, Teperman L, Henegariu O and Krause DS: Liver from bone marrow in humans. Hepatology 32: 11-16, 2000.

5. Orlic D, Kajstura J, Chimenti S, Jakoniuk I, Anderson SM, Li B, Pickel J, McKay R, Nadal-Ginard B, Bodine DM, Leri A and Anversa P: Bone marrow cells regenerate infarcted myocardium. Nature 410: 701-705, 2001.

6. Eglitis MA and Mezey E: Hematopoietic cells differentiate into both microglia and macroglia in the brains of adult mice. Proc Natl Acad Sci USA 94: 4080-4085, 1997.

7. Krause DS, Theise ND, Collector MI, Henegariu O, Hwang S, Gardner R, Neutzel S and Sharkis SJ: Multi-organ, multi-lineage engraftment by a single bone marrow-derived stem cell. Cell 105: 369-377, 2001. 
8. Schwartz E, Reyes M, Koodie L, Jiang Y, Blackstad M, Lund T, Lenvik T, Johnson S, Hu WS and Verfaillie CM: Multipotent adult progenitor cells from bone marrow differentiate into functional hepatocyte-like cells. J Clin Invest 109: 1291-1302, 2002.

9. Thorgeirsson SS and Grisham JW: Hematopoietic cells as hepatocyte stem cells: a critical review of the evidence. Hepatology 43: 2-8, 2006.

10. Zuk PA, Zhu M, Mizuno H, Huang J, Futrell JW, Katz AW, Behnaim P, Lorenz HP and Hedrick MH: Multilineage cells from human adipose tissue: implications for cell-based therapies. Tissue Eng 7: 211-228, 2001.

11. Pittenger MF, Mackay AM, Beck SC, Jaiswal RK, Douglas R, Mosca JD, Moorman MA, Simonetti DW, Craig S and Marshak DR: Multilineage potential of adult human mesenchymal stem cells Science 284: 143-147, 1999.

12. Bieback K, Kern S, Klüter H and Eichler H: Critical parameters for the isolation of mesenchymal stem cells from umbilical cord blood. Stem Cells 22: 625-634, 2004

13. de Coppi P, Bartsch G, Siddiqui MM, Xu T, Santos CC, Perin L, Mostoslavsky G, Serre AC, Snyder EY, Yoo JJ, Furth ME, Soker S and Atala A: Isolation of amniotic stem cell lines with potential for therapy. Nat Biotechnol 25: 100-106, 2007.

14. In 't Anker PS, Scherjon SA, Kleijburg-van der Keur C, de GrootSwings GM, Claas FH, Fibbe WE and Kanhai HH: Isolation of mesenchymal stem cells of fetal or maternal origin from human placenta. Stem Cells 22: 1338-1345, 2004.

15. Lee KD, Kuo TK, Whang-Peng J, Chung YF, Lin CT, Chou SH, Chen JR, Chen YP and Lee OK: In vitro hepatic differentiation of human mesenchymal stem cells. Hepatology 40: 1275-1284, 2004.

16. Wang X, Ge S, McNamara G, Hao QL, Crooks GM and Nolta JA: Albumin-expressing hepatocyte-like cells develop in the livers of immune-deficient mice that received transplants of highly purified human hematopoietic stem cells. Blood 101: 4201-4208, 2003.

17. Hengstler JG, Brulport M, Schormann W, Bauer A, Hermes M, Nussler AK, Fandrich F, Ruhnke M, Ungefroren H, Griffin L, Bockamp E, Oesch F and von Mach MA: Generation of human hepatocytes by stem cell technology: definition of the hepatocyte. Expert Opin Drug Metab Toxicol 1: 61-74, 2005.

18. Fang B, Shi M, Liao L, Yang S, Liu Y and Zhao RC: Systemic infusion of FLK1(+) mesenchymal stem cells ameliorate carbon tetrachloride-induced liver fibrosis in mice. Transplantation 78: $83-88,2004$
19. Seo MJ, Suh SY, Bae YC and Jung JS: Differentiation of human adipose stromal cells into hepatic lineage in vitro and in vivo. Biochem Biophys Res Commun 328: 258-264, 2005.

20. di Bonzo LV, Ferrero I, Cravanzola C, Mareschi K, Rustichell D, Novo E, Sanavio F, Cannito S, Zamara E, Bertero M, Davit A, Francica S, Novelli F, Colombatto S, Fagioli F and Parola M: Human mesenchymal stem cells as a two-edged sword in hepatic regenerative medicine: engraftment and hepatocyte differentiation versus profibrogenic potential. Gut 57: 223-231, 2008

21. Nakamura T, Torimura T, Sakamoto M, Hashimoto O, Taniguchi E, Inoue K, Sakata R, Kumashiro R, Murohara T, Ueno $T$ and Sata M: Significance and therapeutic potential of endothelial progenitor cell transplantation in a cirrhotic liver rat model. Gastroenterology 133: 91-107, 2007.

22. Sakaida I, Terai S, Yamamoto N, Aoyama K, Ishikawa T, Nishina $\mathrm{H}$ and Okita $\mathrm{K}$ : Transplantation of bone marrow cells reduces CCl4-induced liver fibrosis in mice. Hepatology 40: 1304-1311, 2004.

23. Lee OK, Kuo TK, Chen WM, Lee KD, Hsieh SL and Chen TH: Isolation of multipotent mesenchymal stem cells from umbilical cord blood. Blood 103: 1669-1675, 2004

24. Hong SH, Gang EJ, Jeong JA, Ahn C, Hwang SH, Yang IH, Park $\mathrm{HK}$, Han $\mathrm{H}$ and Kim $\mathrm{H}$ : In vitro differentiation of human umbilical cord blood-derived mesenchymal stem cells into hepatocyte-like cells. Biochem Biophys Res Commun 330: 1153-1161, 2005.

25. Snykers S, Vanhaecke T, Papeleu P, Luttun A, Jiang Y, Vander Heyden Y, Verfaillie C and Rogiers V: Sequential exposure to cytokines reflecting embryogenesis: the key for in vitro differentiation of adult bone marrow stem cells into functional hepatocyte-like cells. Toxicol Sci 94: 330-341, 2006.

26. Oyagi S, Hirose M, Kojima M, Okuyama M, Kawase M, Nakamura T, Ohgushi $\mathrm{H}$ and Yagi K: Therapeutic effect of transplanting HGF-treated bone marrow mesenchymal cells into CCl4-injured rats. J Hepatol 44: 742-748, 2006.

27. Russo FP, Alison MR, Bigger BW, Amofah E, Florou A, Amin F, Bou-Gharios G, Jeffery R, Iredale JP and Forbes SJ: The bone marrow functionally contributes to liver fibrosis. Gastroenterology 130: 1807-1821, 2006. 